\title{
Traços de modernidade em obras de Janáček, Debussy, Schoenberg e Ligeti
}

\author{
Zélia Chueke* \\ Universidade Federal do Paraná
}

\begin{abstract}
Resumo:
A produção musical de nosso tempo, a partir da virada do século XIX-XX, reflete a necessidade - consciente ou inconsciente - da parte de compositores, intérpretes e público, da novidade. Ao lado desta necessidade, observa-se certo medo do desconhecido, compreensível, até certo ponto, no que diz respeito aos ouvidos leigos. mas certamente intrigante se observado em profissionais da música, sobretudo os intérpretes, enquanto mediadores entre compositores e ouvintes. Através do testemunho de alguns intérpretes e da exploração de obras de Janáček, Debussy. Schoenberg e Ligeti - compositores representativos de diferentes épocas recentes partilho neste trabalho a constatação de que a modernidade não se revela necessariamente através de aspectos de notação, forma ou estrutura, e nem mesmo de linguagem, mas na mensagem musical propriamente dita, no conteúdo do discurso musical. Partindo-se deste princípio, o primeiro passo para a percepção, compreensão e abertura ao novo na música seria uma renovação dos parâmetros de escuta. primeiramente da parte dos intérpretes, que poderão desta forma despertar os ouvidos do público de hoje, "perdidos no passado", para os prazeres da modernidade.
\end{abstract}

Palavras-chave: música do século $X X$ : modernidade e tradição: análise para intérpretes

*Zélia Chueke, Pós-Doutora pela Université de Paris-Sorbonne, Paris IV. leciona no Departamento de Música e Artes Visuais da UFPR e participa ativamente como Pesquisadora Associada ao Observatoire Musical Français - Sorbonne, Paris IV desde 2003. Em suas atividades, vem atuando como concertista e pesquisadora no Brasil, na Europa e nos Estados Unidos, apresentando-se em recitais solo e de câmera e concertos com orquestra, incluindo festivais de música contemporânea e gravaçōes para rádio e TV. Contribui regularmente como conferencista, organizadora e editora em congressos e colóquios, com trabalhos publicados em três idiomas. Lecionou na New World School of Arts e na University of Miamientre 1993 e 2002. 


\section{Em busca do novo}

Este trabalho representa uma pequena parte da pesquisa intitulada " $O$ Medo do Desconhecido", que venho desenvolvendo desde 2005, com a colaboração de pianistas, compositores e musicólogos, em torno da recepção e compreensão da música de nosso tempo, sobretudo por parte dos intérpretes, no papel de mediadores entre compositores e ouvintes.

A produção musical de nosso tempo ainda não atingiu um estado de desenvolvimento, riqueza ou flexibilidade que the confira a devida maturidade para que seja definido um estilo; tampouco chegou a estabelecer uma nova linguagem, cuja necessidade se fez sentir - consciente ou inconscientemente desde o começo do século XX, por parte de compositores, intérpretes e ouvintes. Neste processo de busca, a música - assim como as outras artes - percorreu caminhos diversos, por vezes totalmente opostos, experimentando infinitas opçōes. Algumas obras, independentemente da época em que foram compostas, devido à sua originalidade e genialidade, impuseram-se a ponto de serem consideradas até hoje - já na primeira metade do século XXI como sendo "do nosso tempo". É justamente nesta diversidade que reside a riqueza deste período; novas possibilidades são exploradas, ao mesmo tempo em que se reinterpreta o passado, reorganizando aquisições anteriores ao invés de inventarse ou experimentar-se um vocabulário totalmente inovador. Aparentemente esta visita ao passado é a mais recente tendência da atualidade, como podemos constatar pelos comentários do crítico e curador francês Nicolas Bourriaud, em sua entrevista sobre a Bienal de São Paulo (2006):

Da mesma forma que as vanguardas do início do século $X X$ foram baseadas na idéia do futuro, é muito possível que a modernidade do século $X X I$ seja baseada em leituras do passado. No século passado, o futuro era o modelo de leitura do presente, hoje, talvez, o passado seja o modelo de leitura. Isto ocorre por conta da padronização do planeta, que apaga a memória, e a melhor forma de lutar contra isso é não voltar ao passado, mas ler o passado no presente, buscar novos itinerários no passado [...]. 
De fato, vários aspectos mencionados por diferentes intérpretes como típicos da chamada música contemporânea, são observáveis na obra de compositores de diferentes períodos, entre as duas últimas viradas de século, revelando certas coincidências no discurso musical, e demonstrando que a modernidade não se impõe necessariamente pela introdução de novas formas de notação, organização ou estrutura, mas pela novidade do conteúdo do discurso musical propriamente dito. Para ilustrar esta constatação, escolhi algumas obras dos quatro compositores citados no título deste texto que, utilizando-se dos mesmos recursos de notação, registraram, entre 1862 a 1991, idéias musicais completamente diferentes, com fortes traços de modernidade.

Antes de prosseguir, observo que devemos entender modernidade da maneira mais abrangente possivel, como uma extensão da tradição, ou algo que está à frente do tempo presente, ou ainda o que não soa familiar. Estas três opções podem ser combinadas em uma, tendo em mente que a mesma música que soa moderna para uns, pode não soar moderna para outros, dependendo do contexto onde é introduzida e/ou do background do receptor. Do ponto de vista do público em geral, o "medo do desconhecido" é bastante compreensível e até previsivel, mas é intrigante observá-lo em intérpretes, cuja formação musical deveria torná-los ao menos abertos ao inusitado, independentemente de familiaridade ou afinidade. De maneira geral, esta falta de abertura é consequência da falta de discernimento sobre "o que escutar" numa obra, ferramenta indispensável para uma interpretação consistente de qualquer tipo de repertório.

A situação se define: nossos ouvidos estão perdidos no presente, sem pertencer ao passado. Ao mesmo tempo, a música com a qual deveríamos estar familiarizados nos soa estranha, apesar de ser representativa de nosso tempo.

Este assunto foi abordado ao longo do século XX sob diversos ângulos.' e a colocação de Tabachnick (1991, p. 148 -149) ainda não pode ser considerada como uma realidade:

1 Para uma discussão desse tema, consultar: Schoezer; Scriabine (1959), Cook (1994, p. 64-95) e Chueke (2003, v. 3. p. 100-104). 
O compositor, mais do que uma testemunha de seu tempo, é um precursor, e antes de tudo, um mediador. [...] O intérprete, diante da obra proposta. deve abrir-se ao imaginário, ao espirito inventivo e não racionalizar a qualquer preço. Ele pode vibrar com as mesmas fontes de inspiração que provêem de um mesmo mundo espiritual, próprio de seu tempo. Enquanto mediador, o músico recria e torna sua, a obra que ele poderia ter escrito. Deste ponto de vista, o intérprete está muito mais próximo de uma primeira audição de seu tempo do que das obras do passado.

\section{Notação, linguagem ou conteúdo?}

Em parte devido à indefinição do conceito de "novo" e da expressão "música contemporânea", permanece a pergunta: o que nos parece moderno no que diz respeito à música composta nos séculos XX e XXI?

- Quanto à notação: visto que nenhum compositor é realmente indiferente ao risco de ter sua obra executada de maneiras radicalmente diferentes a cada apresentação - a não ser que sua proposta seja exatamente esta -, a questão da notaçāo prova-se mais diretamente ligada à precisāo no registro das idéias musicais do que a qualquer aspecto particularmente inovador.

- Quanto à linguagem: vale a pena questionar se a busca de novas alternativas tem como motivo a exaustão de possibilidades da linguagem vigente. As riquezas de uma linguagem chegam a se extinguir completamente?

Crer que abandonamos uma sintaxe, uma técnica, simplesmente porque ela não nos oferece mais recursos seria uma concepção demasiadamente simplista. [...] O empobrecimento da linguagem musical, consecutivo ao abandono dos modos antigos, foi compensado pela possibilidade de modulação e transposição para as diversas tonalidades. Portanto, é através da produção musical, e não da sociologia ou da psicologia que devemos considerar as inovações que ocorreram na música no decorrer de sua história. (Schloezer, 1959, p. 16-17).

Baseando-me na última frase desta citação, procurei registrar algumas pesquisas relacionadas ao campo da psicologia e da sociologia, antes de explorar a produção musical propriamente dita. Estas pesquisas abordam, em sua maioria, o aspecto mais freqüentemente mencionado quando são evocadas as inovaçōes 
surgidas na Música a partir do início do século XX: o contraste entre o conforto da tonalidade e a perplexidade causada pela falta de referências tonais.

Dowling (2001, p. 113), por exemplo, explica que "quando escutamos música própria de nossa cultura, ouvimos melodias compostas de alturas significativas e não simplesmente som, desprovido de interpretação." Entre estes parâmetros, Dowling inclui a tonalidade - partindo e retornando à tônica - e a forma (por exemplo. AABA para cançōes populares, ou ABA para as formas sonata).

Davidson e Welsh (2001, p. 261) enfocam o problema da formação de futuros profissionais quase que exclusivamente concentrada no estudo de harmonia e contraponto dentro da moldura tonal. Segundo as autoras, mesmo constatando-se a diferença entre os processos de escuta, interpretação e composição, influenciados pelos parâmetros de tonalidade, devido à nossa cultura, os elementos tonais são mais facilmente processados, reconhecidos e memorizados do que os atonais.

Aparentemente isto se aplica tanto aos ouvidos experimentados quanto aos leigos. Jamshed Bharucha (1994, p. 221) comprova que mesmo para os compositores - que tendo sido expostos a diversos gêneros musicais, inclusive alguns muito distantes da harmonia tonal, armazenaram os mais diversos esquemas em sua memória auditiva - é praticamente impossível escapar-se da harmonia tonal enquanto participantes da civilização ocidental.

No entanto, estudos como o de Clarke e Krumahnsl (apud Cook, 1994, p. 72) sobre a verbalização da escuta de obras de Stockhausen e Mozart, enfatizando aspectos do discurso sonoro sem nenhuma referência a aspectos tonais, provam que os ouvidos de hoje. uma vez libertos do aprisionamento de conceitos e parâmetros, podem perceber a música de maneira muito mais livre do que nos levariam a crer algumas destas pesquisas. 


\section{Parâmetros de escuta}

A compreensão da mensagem musical torna-se possivel através do armazenamento, em nosso ouvido interior, de coincidências e padrōes relativos ao material sonoro que somos capazes de reconhecer. Este processo de reconhecimento varia de acordo com aspectos gerais do cenário sócio-cultural e outros mais específicos, como a própria formação musical.

É o que podemos observar através dos dois comentários diametralmente opostos, a respeito da música de Brahms., pronunciados por seus contemporâneos. O primeiro, de alguém que também é um compositor à frente de seu tempo; o segundo, de um crítico que representa a demanda, a expectativa auditiva, do público de $1859 .^{3}$

Eis alguém que vem direto de Deus. Tocou para nós suas sonatas, scherzos etc.... em todas revelando uma imaginação exuberante, profundidade de sentimentos, e domínio da forma. (Clara Schumann, apud MacDonald, 1990, p. 15).

[...] uma obra destinada ao túmulo. Esta peça nāo tem como proporcionar prazer [...] não possui nada a oferecer além de desolação desesperançada e aridez [...] por mais de três quartos de hora há que se suportar esta obstínação. esta desorientaçāo. esta tensāo e arrebatamento, este recorte e colagem de frases e ornamentos! [...] A técnica pianística de Herr Brahms nāo satisfaz as demandas às quais temos o direito, no que se refere a um solista de nosso tempo. (Edward Bernsdorf apud MacDonald, 1990, p. 53).

A literatura nos mostra como, um pouco mais tarde, o mesmo tipo de sociedade, na Viena de 1899, rejeitou o Verklaerte Nacht de Schoenberg, fazendo comentários semelhantes: "Soa como se alguém tivesse borrado a tinta ainda fresca da partitura de Tristão e Isolda!" (Burge, 1990, p. 24).

Não foi por acaso que a Sociedade de Músicos Criativos, fundada por Schoenberg em 1904, durou apenas uma temporada. O compositor referiu-se a

\footnotetext{
${ }^{2}$ Neste caso específico, o Concerto para piano e orquestra op. 15, em Ré menor.

${ }^{3}$ Critica publicada no jornal Signale, 27/1/1859, sobre a estréia do mesmo concerto na Gewandhaus, em Leidpzig.
} 
esta rejeição hostil da parte do público, estendendo-a aos intérpretes, que, segundo ele, preferiam "ater-se a obras de efeito comprovado, já acolhidas favoravelmente pelo público." Schoenberg constatou que as possibilidades de se executar música moderna ficavam cada vez mais reduzidas, pois os empresários e promotores de concerto exerciam forte influência na escolha de programas. visando lucros financeiros. O compositor considerava-os inimigos da vida musical, provocando. com a repetição dos mesmos programas, uma falta de interesse do público pela música em geral.

Mais ou menos na mesma época, Debussy rebelava-se abertamente contra a tradição. Burge (1990, p. 4), descreve o contexto parisiense onde, rejeitando a academia, os membros da Societé des Artistes Indépendents promoviam o individualismo, deixando claro que "nenhum pecado é imperdoável, exceto o de não sentir". Burge explica que o inconformismo da Societé e o desafio espiritual dos Simbolistas representavam uma ameaça à complacência burguesa, que, por sua vez, acirrou a revolta da comunidade artística, unindo-os mais ainda e provocando o movimento de vanguarda. Em sua conclusão, o autor explica que os efeitos da música desses dois compositores em suas cidades respectivas foram profundos.

Avançando no tempo, encontramos registros sobre as diferentes reaçōes à música de György Ligeti. Henry Lang (1965, p. 176) nos fala da acolhida do compositor húngaro pelo público alemão. Segundo ele. Ligeti "encontrou a aprovação enquanto defensor de uma nova forma de notação e [de] constantes mudanças na sintaxe musical, renovada a cada obra."

No capítulo dedicado à Espanha, o autor (p. 44) menciona igualmente a divulgação bem sucedida da obra de Schoenberg, Stockhausen e Ligeti no Ateneo de Madrid. No entanto, no capítulo dedicado à Áustria, o relato de Lang é bastante revelador. Ele comenta que, por mais que o estilo de doze sons e o serialismo da escola vienense tivessem se tornado uma linguagem internacional, ela ainda era raramente ouvida no país onde tinham sido estabelecidos seus fundamentos. 
Reflexo desta situação era o fato de que os concertos promovidos por Friedrich Cehra e seu conjunto Die Reihe, que se apresentava ora na Wiener Konzerhaus, ora no Museum des XX Jahrhunderts, representavam praticamente a única possibilidade de informação sobre a música serialista. Os compositores austríacos eram raramente representados, exceto pelas obras de Schoenberg, Berg e Webern; Ligeti, "austríaco por opção", pertencia ao círculo fechado de serialistas que haviam adquirido certa reputação no exterior, embora suas obras fossem raramente ouvidas na Áustria.

Para que fique mais evidente a relatividade do conceito de modernidade, lembremos de Leoš Janáček (1854-1928), compositor e lingüista, residente em Brno na Morávia, que anotava as conversaçōes de pessoas na rua, de crianças conversando entre si; ou as falas de um padeiro, de um mendigo ou de sua própria filha Olga, no leito de morte, transformando-as em música. Desde 1888 Janáček fazia referências à "melodia da fala":

[...] estamos a meio caminho de uma encenação teatral quando citamos as palavras de outra pessoa. Citamos a velocidade da fala, o registro tonal, a subida e a descida da melodia, e assim expressamos diversos estados da mente. [...] A melodia da língua tcheca que soa na fala, que agrada, emociona, esbraveja ou sussurra ternamente [...] (Janáček apud Zemanová, 1993, p. 34).

O nacionalismo de Janáček é evidentemente o ponto de ligação entre sua música e seus conterrâneos, e, no entanto, os parâmetros que o próprio compositor determina para a escuta de seu discurso musical são extremamente originais.

Seu Concertino para piano, dois violinos, viola, clarinete, trompa e fagote foi escrito em 1925. O tema inicial ocupa três compassos, seguido da resposta da trompa em fá. Este curto diálogo é repetido três vezes, antes de se desenvolver em stretto por dois compassos e tornar a se repetir por três vezes, mais enfaticamente, pois a linha do piano, antes unicamente na mão esquerda, agora começa com um acorde e é oitavada pela mão esquerda. A mudança de 
moderato para più mosso introduz um caráter mais agressivo, culminando num trinado cresc., accel. (Exemplos 1a, 1b, 1c e 1d).

Exemplo 1a Concertino, comp. 1-3

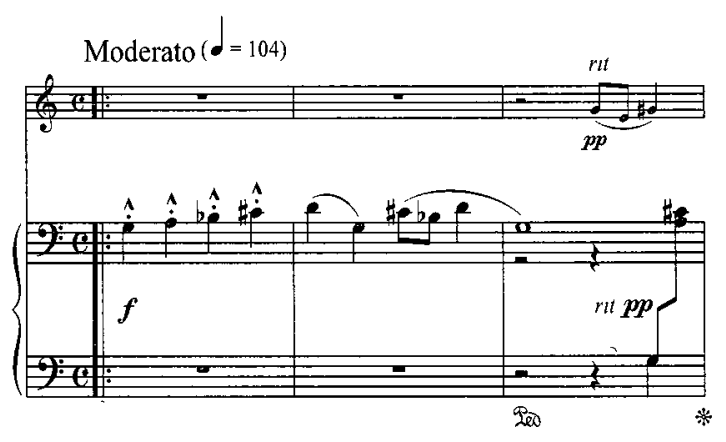

Exemplo 1b Concertino, comp. 9.4-10

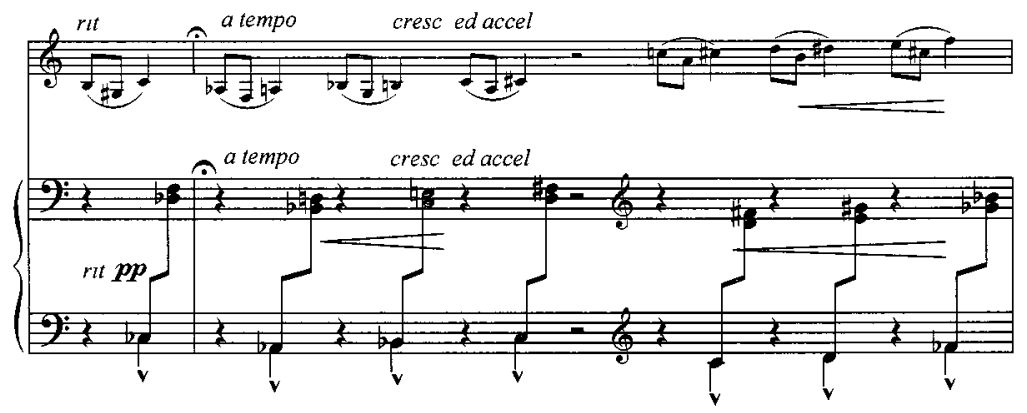

Exemplo 1c Concertino, comp. 11-13

Più mosso $(\downarrow=152)$

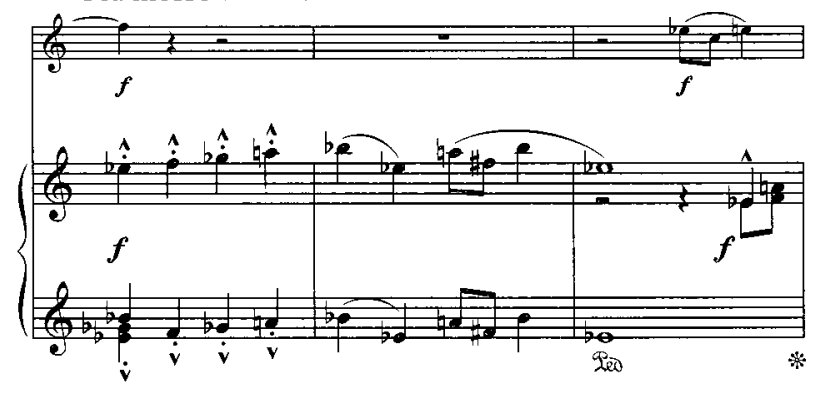


Exemplo 1d Concertino, comp. 19.4-21.1

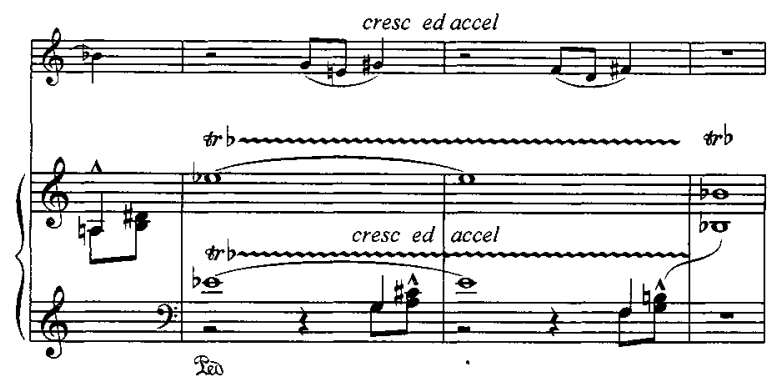

O diálogo entre os instrumentos torna-se mais acirrado, até que toda a irritação se dissipa no rubato do piano, chegando a um trecho em $p p$, dolcissimo. polirrítmico e romântico (Exemplo 2a). O contraste aparece em più mosso, com a repetição irritada de um motivo formado de duas colcheias e uma semínima pela trompa, paralelamente a uma narrativa animada do piano, quase irônica (Exemplo 2b). Segue-se um solo de piano ad. lib., rude e prepotente, após o que o trecho contrastante em più mosso retorna, assim como o tema inicial, que é repetido mais três vezes, com o piano a tempo em ff. $m f$ e $p p$, ecoado pela trompa, sempre em $p p$, rit., até o último suspiro triste e conformado dos dois instrumentos em $p p$, rit.

Exemplo 2a Concertino, comp. 41

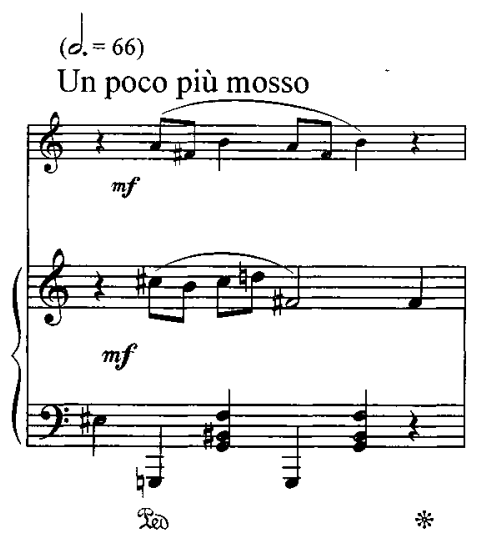


Exemplo 2b Concertino, comp. 24-25

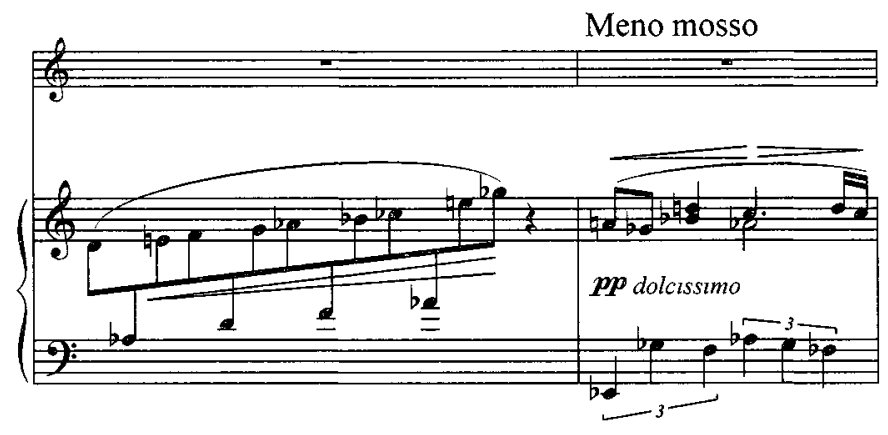

Esta minha descrição, baseada no material sonoro registrado na partitura, está em sintonia com o que Janáček (apud Zemanová, 1993, p. 108, 109) nos revela sobre mudanças de humor e expressão confusa de sentimentos, enquanto representação musical de uma situação vivida por ele próprio:

Era primavera, e bloqueamos a entrada da toca de um porco espinho numa árvore, onde ele havia instalado confortavelmente, seu ninho. Ele ficou completamente transtornado! Nāo conseguia compreender o que se passava. É por isso que minha trompa persiste neste tema mal - humorado.

A respeito do segundo movimento - para clarineta e piano - o compositor (apud Zemanová, p. 109) nos fala de um esquilo que "saltita de uma árvore para outra"; o estado de espírito alegre e despreocupado é divido entre piano e clarineta e interrompido apenas por alguns compassos onde, segundo o compositor, o esquilo "resmunga dentro de sua jaula, como minha clarineta", para depois libertar-se e "dançar para entreter as crianças". O terceiro movimento representa, "através das cordas do piano, [...] os grandes olhos arregalados de corujas pequenas e grandes, insolentemente fixos." O último movimento, segundo o compositor, é como "as brigas por uma moeda nos contos de fada" citando provavelmente um conto da sua tradição nacional.

A verdade é que esta música soa extremamente moderna, mesmo para os ouvidos de hoje, e isto se deve essencialmente ao conteúdo do discurso musical, ou seja, à mensagem musical propriamente dita. A relação entre modernidade $\mathrm{e}$ 
contexto cultural fica evidente, uma vez que, tendo-se estabelecido um ponto de referência que proporcione uma sensação de familiaridade - e conseqüentemente de segurança - seja qual for a linguagem utilizada, a aceitação dos ouvintes é praticamente garantida. Certamente é na cultura nacional que devemos buscar os parâmetros que irão esclarecer e enriquecer a escuta da música de Janáček. exatamente os mesmos parâmetros que lhe proporcionaram a acolhida de seus compatriotas.

De um ponto de vista semelhante, os relatos de De La Laurencie (1904. p. 141-149), no Currier Musical, demonstram os motivos pelos quais a música de Debussy foi perfeitamente aceita pelo público da época. Os parâmetros são os da tradição tonal, justificáveis na época. Comparando-os com os comentários relativos à obra de Schoenberg, podemos constatar muitas semélhanças, partindo da definição de atonalidade como não definição ou estabelecimento de uma tonalidade a ponto de se tornar um guia através do discurso sonoro, um ponto de apoio ou referência.

Comparemos então os comentários sobre o pensamento musical de Debussy e Schoenberg da parte dos próprios compositores e de estudiosos da Música:

\begin{abstract}
Para os ouvintes, a música de Debussy é simplesmente música. Nenhum dos tratados de harmonia do mundo pode impedi-lo. [...] Em lugar da distinção fundamental entre acordes consonantes e dissonantes, todos os acordes são considerados como consonantes. (Landormy, 1910, p. 99).

[...] emprego de acordes que pediriam uma resoluçāo, tratando-os de maneira inédita sem levar em conta nenhuma regra de gramática musical, derruba os hábitos adquiridos e engendra uma música que "soa" diferente das outras. [...] Uma das tendências mais características de Debussy consiste no emprego de ressonâncias naturais, formadas de sons harmônicos [...]. Podemos considerar que a dissonância é apenas uma consonância que se ignora. (De La Laurencie, 1904, p. 142-144).
\end{abstract}

Ou seja, apesar de sua contestação proposital das tradiçōes harmônicas e formais decorrentes da influência austro-germânica em voga em toda a Europa. 
que inevitavelmente impregnavam os ouvidos da época, a música de Debussy não agrediu os ouvintes.

O mesmo não pode ser dito em relação à música de Schoenberg. No momento em que introduziu a novidade de desligar-se da linguagem tonal, por mais natural que este processo tenha sido, a aceitação de sua música por parte dos ouvintes tornou-se dificil. Haimo (1996, p. 72) nos lembra que "o nascimento da tonalidade no pensamento de Schoenberg não foi abrupto: a sintaxe e o idioma tipicamente tonal foram gradualmente desaparecendo, dando lugar a procedimentos não tonais." Por exemplo, em Mádchenlied op. 6. n. 3. após ter estabelecido o tom de $\mathrm{Mi}$ menor no primeiro compasso (inclusive de acordo com a armadura de clave). Schoenberg explora uma infinidade de possibilidades harmônicas que não definem uma tonalidade em particular.

Da mesma forma, em Nuages, primeiro dos Nocturnes de Debussy, encontramos uma série de acordes perfeitos com numerosas quintas paralelas que desviam nossos ouvidos do tom de $\mathrm{Si}$ menor sugerido pela armadura de clave, embora de fato esta tonalidade esteja presente nos primeiros compassos (com a sensivel resolvendo na tônica logo no primeiro compasso). Porém, o cromatismo que introduz a nota fá bequadro (comp. 3) traz a possibilidade de outras tonalidades. Estas idas e vindas levaram M. Marnold (apud Laurencie, 1904) a sugerir um "terceiro modo", denominado "modo maior diminuído", que se caracterizaria pela alteração da quinta (si-ré-fá em lugar de si-ré-fa\#).

Esta indefinição de tonalidade, também pode ser observada em Jardins sous la Pluie, terceira peça de Estampes, onde o tom de Mi menor da primeira exposição do tema da tradicional canção de ninar francesa "Do, do, l'enfant do" (comp. 1-5) é esquecido rapidamente, não apenas pelo fá bequadro que se instala no baixo por dois compassos, retornando mais tarde, mas sobretudo por não ser a tonalidade necessariamente o parâmetro de escuta mais recomendado para este trecho da peça. No caso de Nuages, a peça promove timbres, contornos melódicos e variações do tema, que Laurencie (p. 147) chama de "evolucionismo musical". 
Como se a própria música não fosse suficiente para sustentar meu argumento. não podemos desconsiderar outros aspectos comprovadamente essenciais para o próprio Debussy (1911), que declara: "chego a amar imagens e música com a mesma intensidade". ${ }^{4}$ Goubault (2002, p. 10-12) nos chama a atenção para a "imagem" da notação:

O grafismo da partitura fala aos olhos tanto quanto ao ouvido: a escritura representa o papel de um espelho colocado entre o mundo sensível e a arte dos sons [...] em seus títulos e subtítulos, emprega vocabulário das artes plásticas e da representação gráfica: arabesques, estampes, esquises, images.

Seus doze estudos para piano são o perfeito exemplo desta sugestão gráfica. De acordo com a idéia de "incorporar" a mensagem musical, a síntese de cada um deles está baseada em aspectos muito pouco ortodoxos, uma vez que os elementos explorados, embora perfeitamente conhecidos dos intérpretes - cinco dedos, terças, quartas, sextas, oitavas, oito dedos, cromatismo, ornamentos, notas repetidas, sonoridades opostas, arpejos e acordes - são trabalhados de forma extremamente inovadora, enfocando os efeitos ao invés dos recursos.

No entanto, os parâmetros de escuta pouco mudaram na Europa desde a virada do século (XIX-XX), e os ouvidos tonais, ofendidos pela instabilidade desse tipo de discurso harmônico, deixam de perceber e aproveitar o novo material, o que seria muito mais essencial para a compreensão do texto musical. Jarocinsky (apud Barraqué, 1994, p. 12), afirma que "os ouvintes de hoje escutam a música de Debussy da mesma forma limitada que o público dos primeiros trinta anos do século XX." O mesmo tópico é abordado por Madurell (1999) em "Musique d'aujourd'hui oreille d'hier" (Música de hoje, ouvidos de ontem). Este fato, se passivel de aceitação no que diz respeito aos ouvidos leigos, não deveria sequer ser cogitado entre os intérpretes profissionais, que além de supostamente terem experimentado e vivido - ao menos através de sua formação - a evolução da

${ }^{4}$ Lettres. Paris: Hermann, 1980, p. 207. 
produção musical, precisam saber captar a mensagem musical pelo ângulo que mais valorize o conteúdo.

\section{O intérprete como narrador: a escolha da escuta}

Diversas alusões já foram feitas à função do intérprete como narrador. ${ }^{5}$ não necessariamente na forma explícita de Janáček, que realmente se inspira na fala para registrar o discurso musical, mas como um narrador de idéias musicais. Independentemente do estilo ou do compositor, o primeiro passo do relacionamento do intérprete com uma obra, principalmente se esta for inédita, é a definição, através de uma primeira exploração da partitura, de um fio condutor. uma linha de coerência que o conduza pelo discurso sonoro, fazendo-o capaz de mais tarde conduzir os ouvintes pelo mesmo caminho. Como um ator que se prepara para incorporar um personagem, o ideal seria que as idéias musicais registradas na partitura fossem percebidas primeiramente como um todo (no caso do ator, a trama e seu desfecho), num processo de síntese, para que depois sejam explorados os detalhes. Este é o objetivo principal de todos os métodos de análise que foram propostos por Schenker, Schoenberg, Rosen, Hatten e Tarasti, como nos mostra o artigo de Martha Grabocz (1999).

O método de Schenker baseia-se, sobretudo, no contexto harmônico; o de Schoenberg explora mais a forma. Já os mais recentes buscam outros parâmetros, de acordo com o conteúdo de cada obra. possibilitando uma compreensão mais completa e coerente do texto, de acordo com a proposta do compositor. Considero particularmente apropriada, para a exploração da riqueza e da diversidade do discurso musical de nosso tempo, a abordagem de Jacques Viret (2001) sobre a hermenêutica como método de escuta.

O fato é que uma escolha imprópria pode simplesmente desviar o intérprete, e conseqüentemente os ouvintes, das intenções do compositor,

\footnotetext{
${ }^{5}$ Refiro-me em particular a: Rink, John. Translating musical meaning: the performer as narrator. Trabalho apresentado no joint Meeting of the AMS/CBMR/SMT. New York, US. November 1-5, 1995.
} 
perdendo-se, além disto, a oportunidade de que se abram os ouvidos do público para novos discursos e novas possibilidades de escuta.

Joel Lester (apud Rink, 1995, p. 199) nos fala sobre análise e interpretação como opções que delinearão certos aspectos de uma determinada peça, excluindo outros. A meu ver, existem parâmetros, como forma e estrutura, por exemplo, que estão sempre presentes em qualquer opção de execução ou de análise, dependendo da precisão com que são indicados pelo compositor e da acuidade de leitura e percepção do intérprete. Mesmo levando em conta que a riqueza e a imortalidade de uma obra se revelam nas inúmeras interpretaçōes que se manifestam através dos tempos, deve-se levar em conta a essência da obra, geralmente presente em todas estas interpretações, por mais diferentes que soem. Esta essência, se não for captada, e consequentemente transmitida, descaracterizará a obra; daí a responsabilidade do compositor, no que se refere à notação de suas idéias, e do intérprete, no que diz respeito ao discernimento sobre o que ouvir.

De acordo com o pianista Clauder Helffer (apud Gilly, 1991, p. 158), ao querer evitar qualquer semelhança com a música do passado, os compositores buscaram uma maneira de "disfarçá-la", como o fez consequentemente Webern. em seu op. 27, ao interromper o reflexo natural - adquirido através de séculos de evolução do instrumento - diferenciando ré\# de mib.

Deve-se a todo custo evitar uma impressão de nota falsa que poderia ser comparada à aparição de um dó\# num acorde perfeito de dó maior em Mozart ou Haydn. [...] Aprendemos então que cada estilo musical necessita de reflexos particulares e frequentemente contraditórios. (Helffer apud Gilly. 1991, p. 159).

Outros pontos citados por Helffer (apud Gilly. 1991): (a) o fato de alguns compositores deixarem de indicar o número de unidades rítmicas de um compasso, colocando as barras de compasso irregularmente. Estas se tornaram simples pontos de referência visual: "não se trata nunca mais da distinção entre tempos fortes e tempos fracos como acontecia ainda em Schoenberg"; e (b) 
superposiçōes rítmicas, seja para serem executadas com a mesma mão, seja por mãos diferentes, solucionáveis pela aquisição auditiva de cada linha em separado para depois se combinarem sem perder a fluência individual.

Cabe aqui o questionamento: era assim na música de Schoenberg? Era assim antes de Schoenberg? Houve um tempo em que não se esperava (ou se aceitava) que a música fluísse ou que a barra de compasso fosse mais do que um ponto de referência? O próprio Mozart escreveu a seus pais sobre a fluência da execução de seu Concerto para violino KV. 218, em Augsburg, que "fluía como óleo". ${ }^{6}$ Quanto às superposições rítmicas, se o mesmo Helffer já não as tivesse exemplificado através do Estudo Sinfônico n. 11 (comp. 7-8) de Schumann. poderíamos citar não apenas Mozart, mas todos que vieram antes e depois dele, uma vez que a prática musical e a escuta polifônica são inseparáveis, quase como uma única entidade, sendo a segunda indispensável para o êxito da primeira, independentemente de estilo, época ou escrita (explicitamente polifônica ou não).

Para sustentar este argumento, tomo como exemplo algumas obras de Janáček, Debussy, Schoenberg e Ligeti, onde um determinado aspecto - 0 ostinato - foi explorado de diversas formas, unificando a obra, conduzindo a narrativa, ora opondo-se ao tema de forma contrastante, ora unindo-se a ele. valorizando-o. superpondo-se a ele. e assim criando ambientes, provocando suspense, interrompendo, retornando, conformando-se; trazendo a música à vida.

A Sonata 1.X.1905 de Leoš Janáček, compositor e linguiista ardoroso, representa sua reação imediata à morte do jovem Frantisek Pavlik, de vinte anos, durante a dramática manifestação de rua em Brno, em prol do estabelecimento de um universidade tcheca. $O$ título indica a data do acontecimento.

Os dois movimentos restantes (Janáček suprimiu o terceiro) ${ }^{7}$ são intitulados Predtucha (O pressentimento) e Smrt (A morte). O objeto da narrativa aqui não é um fato, o que caracterizaria a peça como um relato, mas uma

\footnotetext{
${ }^{6}$ Mozart, Briefe. Stuttgart: Reclam, 1987. p. 78.

7 Para maiores detalhes, consulte Erismann (1980, p. 115).
} 
sensaçāo. Do acorde inicial, em $p p^{8}$ nasce a melodia, interrompida no quarto compasso pelo motivo do moto perpétuo - fonte de ansiedade, apreensāo e conflito interior que permeia todo o movimento (Exemplo 3a). As palavras estão ausentes; trata-se de um fenômeno quase único, esta capacidade de Janáček de traduzir em linguagem musical todas estas sensaçōes em suas nuances mais sutis.

No primeiro movimento, o motivo interrompe o discurso diversas vezes; após uma terceira tentativa (Exemplo 3b), desenvolve-se, deixando que a apreensão e ansiedade sejam vitoriosas, transformando-se em grupos de semicolcheias que assumem diversas formas nos próximos 24 compassos (11-35), alimentando a angústia contida na melodia em colcheias anunciada nos dois primeiros compassos

Exemplo 3a Sonata 1.X.1905, comp. 1-5

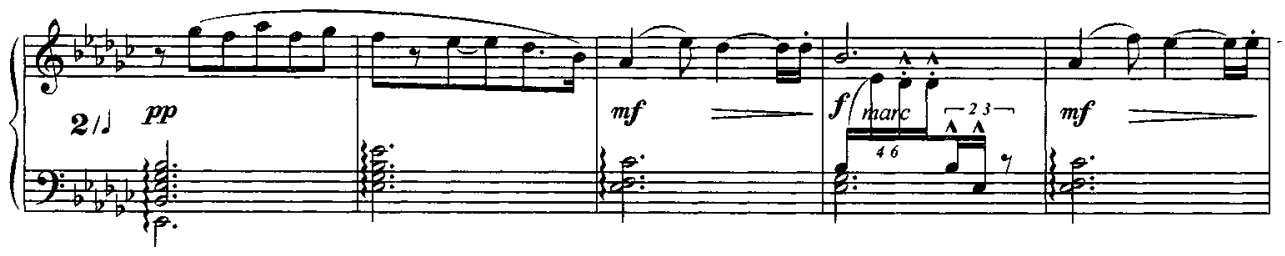

Exemplo 3b Sonata 1.X.1905, comp. 8-10

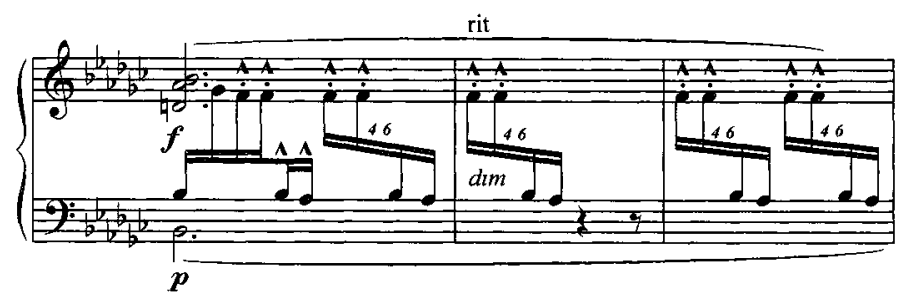

No compasso 37 (notado 36, na edição crítica de 1978), um novo motivo é introduzido abruptamente (Exemplo 4a), estabelecendo com o ostinato uma ansiedade incontrolável: nova cor, nova forma em quiálteras (Exemplo 4b)

\footnotetext{
${ }^{8}$ Erismann (1980) sugere que se deve esperar que todos os harmônicos do acorde inicial se dissipem para dele extrair a melodia.
} 
acompanhando o tema principal em polirritmia, chegando ao clímax, como um grito, explosão da emoção não mais contida. Mas o desespero toma conta de novo, e entramos na re-exposição com o ostinato em semicolcheias (Exemplo 4c). que descansa apenas no compasso 105, numa pequena coda sobre o motivo das quiálteras do segundo ostinato (Exemplo 4d) até o último brado de revolta, em ff - último suspiro antes do acorde final, em ppp.

Exemplo 4a Sonata 1.X.1905, comp. 37

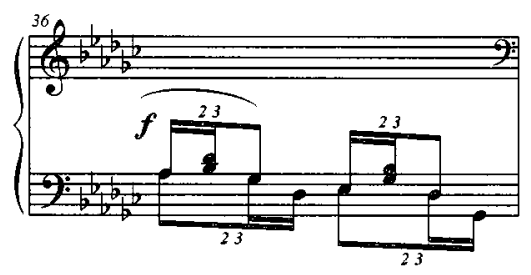

Exemplo 4b Sonata 1.X.1905, comp. 41-42

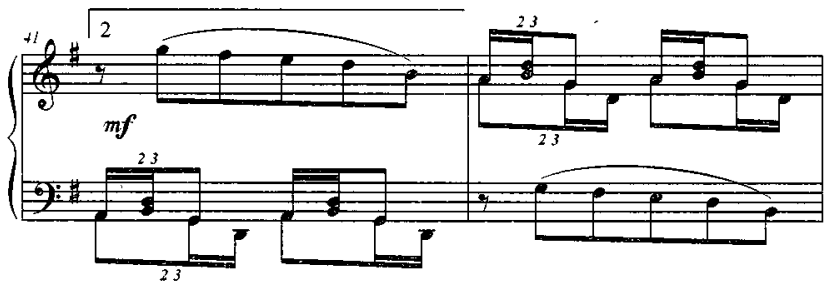

Exemplo 4c Sonata 1.X.1905, comp. 75-77

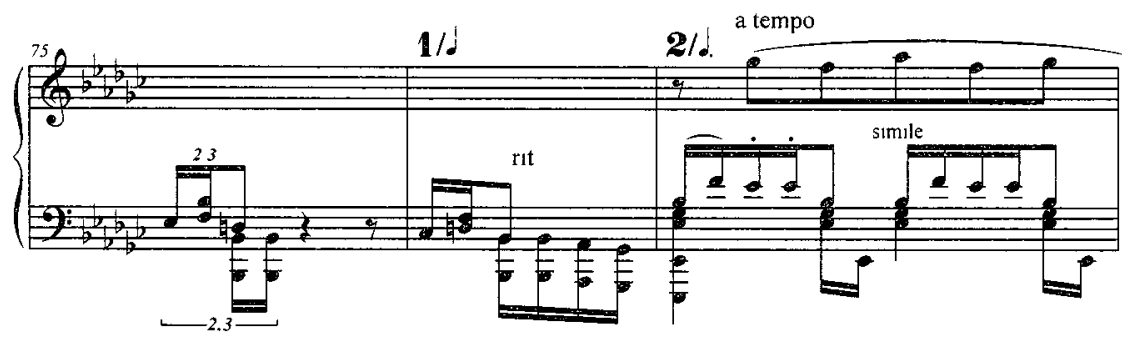


Exemplo 4d Sonata 1.X.1905, comp. 104-105

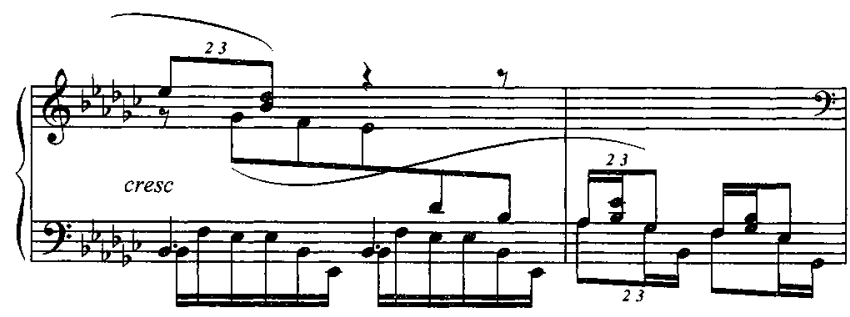

No segundo movimento, a morte, o desconsolo, o lamento revoltado são representadas por um único motivo que permeia todo o discurso (Exemplo $5 \mathrm{a}$ ). 0 ostinato, que começa a se anunciar no compasso 23 , é baseado justamente na parte do ritmo que promove a angústia do motivo principal: fusa pontuada e semifusa (Exemplo 5b). Após vários anúncios, em forma de diálogo entre o motivo principal e seu derivado tenso e ansioso, o desenho se estabelece como moto perpétuo, e a partir do compasso 46 a re-exposição do tema inicial, enriquecida por um eco sincopado, transforma o grito dilacerante, em sff, ainda ofegante, em vários suspiros cada vez mais tênues até o $p p p$. O que permanece. no entanto, não é a conformidade, mas a revolta triste, consciente de sua impotência diante da morte.

Exemplo 5a Sonata 1.X.1905, comp. 1

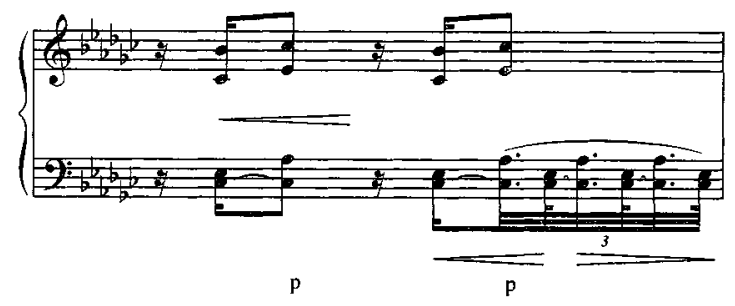


Exemplo 5b Sonata 1.X.1905, comp. 23

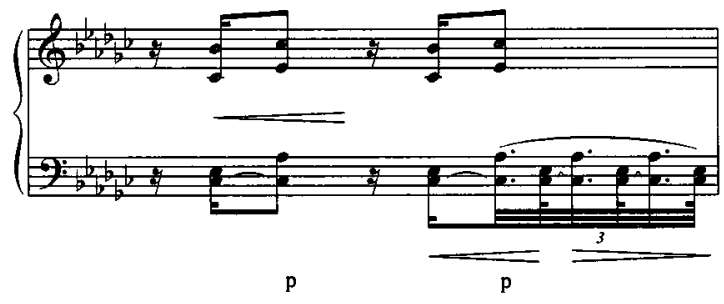

Se o ostinato, na peça de Janáček, carrega a angústia e a morte, Debussy faz uso do mesmo recurso para impulsionar o discurso de Jardins sous la Pluie através de uma chuva ininterrupta. Não apenas observamos, mas somos levados por ela, absorvidos pela cena.

O tema que inspira toda a peça é introduzido nos três primeiros compassos. O contorno melódico é definido pela primeira nota de cada grupo de semicolcheias (comp. 1-36), e é eventualmente sustentado pelo baixo (comp. 49, 14-15). As outras três semicolcheias de cada grupo soam como uma reverberação da nota principal, criando o efeito de pingos de chuva. A dinâmica é 92 pp, colorida por crescendie diminuendi (Exemplo 6).

Exemplo 6 Jardins sous la Pluie, comp. 1-6

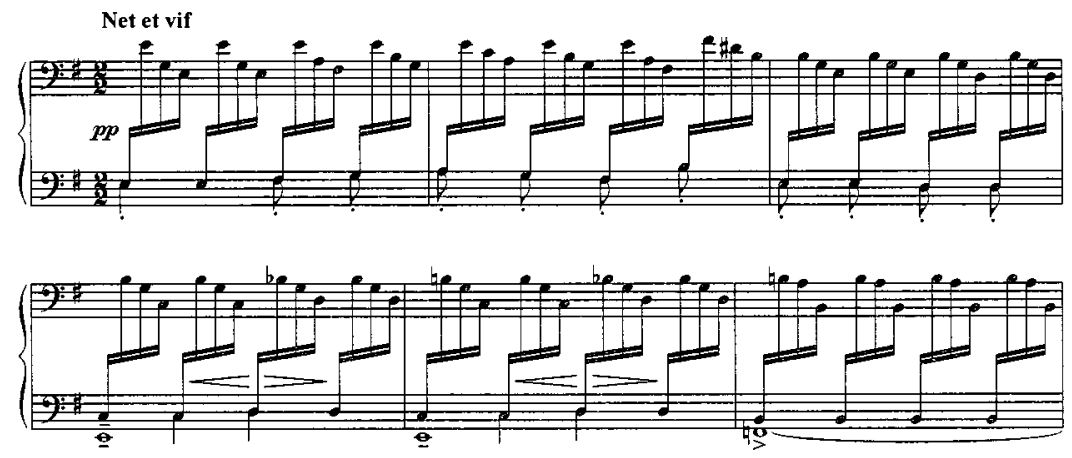


O primeiro $f$ aparece no compasso 24, mas não é sustentado por muito tempo. O compasso 27 introduz a tonalidade de Fá\# maior (Exemplo 7a), onde o tema passa rapidamente sob um foco de luz mais claro: é o movimento contínuo que gera esta fugacidade. A resposta vem no compasso 31, com armadura de Fá\# menor. Embora o efeito de contraste de luz funcione perfeitamente, não é propriamente através da tonalidade que ele acontece, mas sim através do cromatismo descendente no baixo [fá, mi (ao invés de mi\#), ré\#, ré natural, fá2]. Surpreendente, sim, é o f subito (comp. 31), sustentado durante quatro compassos somente, seguido de um dim. molto (comp. 35-37).

A voz do meio começa a interferir (comp. 37-42), estabelecendo um diálogo com o baixo (Exemplo 7b); e os persistentes crescendi e diminuendi finalmente mudam a dinâmica para $f$ quando o tema principal é ouvido em terças no baixo (comp. 43-44). Atingimos o primeiro clímax no ff do compasso 47. Semicolcheias persistentes, sustentadas pelas quintas justas em mínimas no baixo (comp. 47-49) trazem de volta o tema principal em oitavas, em $p p, p$ (comp. 5055).

O efeito de chuva ininterrupta prevalece através do movimento obstinado das semicolcheias. As outras vozes começam a interferir (por exemplo, nos compassos 52-62; colcheias em staccato). O baixo dialoga com a nova linha de terças - as segundas semicolcheias de cada grupo. Outras duas linhas melódicas se estabelecem (comp. 64-70): uma formada pelo baixo e a primeira colcheia de cada grupo de tercinas; outra pelas segundas colcheias de cada grupo (Exemplo 7c).

Exemplo 7a Jardins sous la Pluie, comp. 27

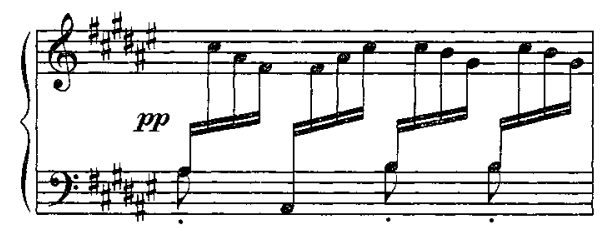


Exemplo 7b Jardins sous la Pluie, comp. 37-38

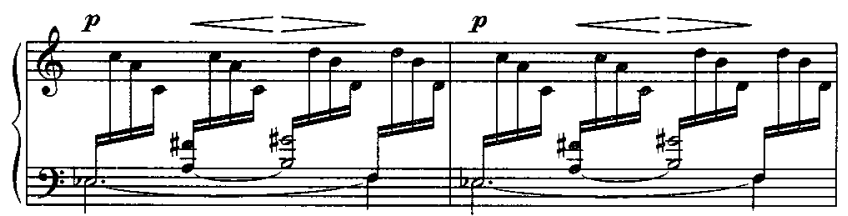

Exemplo 7c Jardins sous la Pluie, comp. 64-65

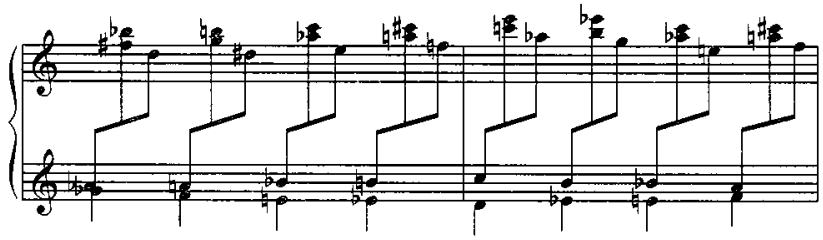

O espírito Net et Vif do começo da peça, intensificado pela indicação de Animez et augmentez peu à peu, é substituído por En se calmant (comp. 73-74) e retorna, embora moins rigoureux (comp. 75-99), quando se estabelece um diálogo entre a melodia da mão direita (comp. 75-81) e o baixo (comp. 93-99); e a melodia da mão esquerda reaparece (comp. 90-97). levando à próxima seção, Mystèrieu, em pp (comp. 100-117). O baixo, depois de ter sustentado as "ondas" em quíntuplas (comp. 100-112), traz o tema (comp. 112-116).

Um efeito surpresa aparece em forma de cascata de semicolcheias nos compassos 116-121. A indicação Rapide retoma o espírito do começo, mais agitado. A cascata se dissolve em trinados no baixo (comp. 122-125), retenu, $p$. più $p, p p$. Trinados surpreendentes com a nota sol2, sustentada e ouvida em $s f$ (comp. 126-132), enriquecem o efeito das oitavas brilhantes da voz aguda (comp. 128-129 e 131-132). Este pequeno motivo, em tercinas e semínimas, que é aumentado na voz grave (comp. 133-135), éclatant, fe ff, leva-nos ao tema principal em tríades scherzando. O mesmo desenho repete-se (comp. 140-146) com um final diferente, infiltrando-se na coda (comp. 147-157) - anunciada na linha do baixo - enquanto o tema é cantado na voz aguda (comp. 147-150). A 
voz do meio (comp. 151-154) leva-nos a um final brilhante (comp. 155-157).

É como contemplar o quadro de um jardim sob a chuva; este é o significado da palavra Estampe(s): impressão. gravura. É a música que constrói a cena, formando uma única entidade com a imagem. Uma se nutre da outra; quanto mais contemplamos o quadro, mais rica se torna a imagem sonora, e viceversa.

O próximo exemplo é a segunda peça do op. 11, de Schoenberg, onde o ostinato mais uma vez promove a coesão da peça, garantindo seu caráter reflexivo e questionador.

As tercinas estabelecem o caráter do discurso e introduzem o primeiro tema (comp. 1-4.1), interrompendo-se oportunamente para dar lugar à resposta ao tema proposto (comp. 5-6.1), conferindo-lhe o devido suspense, sustentando suas reiterações (comp. 6.4.2) e as variações de sua finalização (Exemplo 8a); interrompendo-se novamente para a aparição convicta do tema em acordes distribuidos entre as duas mãos e propositadamente desviando nossos ouvidos de qualquer sensação de tonalidade; o que importa é o suspense criado por cada acorde.

Exemplo 8a Klavierstücke op. 11, 11, comp. 1-6

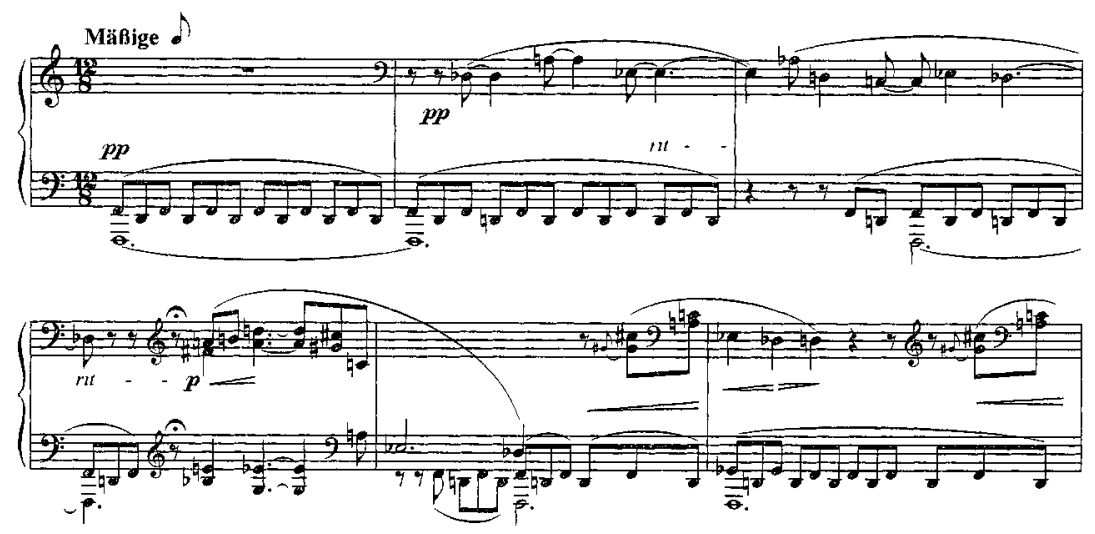


O tema é reapresentado integralmente (comp. 13.3-15), mas sua entrada soa mais significativa sem o ostinato, que aparece depois de soarem as primeiras notas. Segue-se uma variação do tema; e embora o ostinato seja interrompido. ele permanece implícito nas figuras em tercinas que sustentam o fluxo do discurso obstinado e reflexivo, caminhando para o final. Retorna na voz intermediária (comp. 20-24) enquanto o tema se divide entre as duas vozes (grave e aguda), é interrompido (comp. 25) e retorna no registro grave (comp. 26) - um semitom acima de sua primeira aparição - sustentando uma variação do segundo tema.

O compasso 29 muda a métrica de $12 / 8$ para 4/4, e o primeiro tema surge novamente, acompanhado de variações, em 12/8 (comp. 31-32). O tema repete-se (comp. 33) com algumas modificações no ritmo e na finalização, reaparecendo em outro registro (comp. 35-38). O compasso 39 então interrompe o fluxo bruscamente, com seu motivo de semicolcheias, e o ostinato começa a se insinuar, como no compasso 16 , em outro registro.

O segundo tema retorna no compasso 45, onde o ostinato de sua primeira aparição é substituído por um trinado que aumenta a tensão. O motivo do compasso 39 retorna com algumas variações, levando aos compassos 50-51. onde reaparece o $1^{\circ}$ tema, sem suas variaçōes (comp. 50-61); o $2^{\circ}$ tema retorna, $9601^{\circ}$ se impõe (comp. 63-64), mas é a célula do $2^{\circ}$ tema que termina a peça (Exemplo 8b). A função do ostinato é, ao mesmo tempo, definir o caráter da peça e valorizar os temas, entrelaçando-se com eles e suas variaçōes. enriquecendo o contorno melódico.

Exemplo 8b Klavierstücke op. 11, II, comp. 65.4 - 66

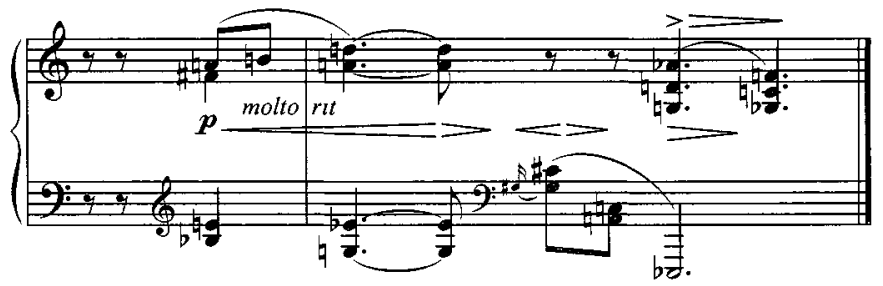


Como na peça de Schoenberg, o ostinato do Estudo n. 4 de György Ligeti, Fanfares, garante o caráter da peça e ainda mais intensamente, por ser realmente ininterrupto (Exemplo 9), impulsiona o discurso e a escuta. Os acentos dos dois planos sonoros principais nunca coincidem, exceto numa parte central específica, criando tensão e relaxamento, mas por poucos compassos (133-138).

Exemplo 9 Fanfares, comp. 1-4

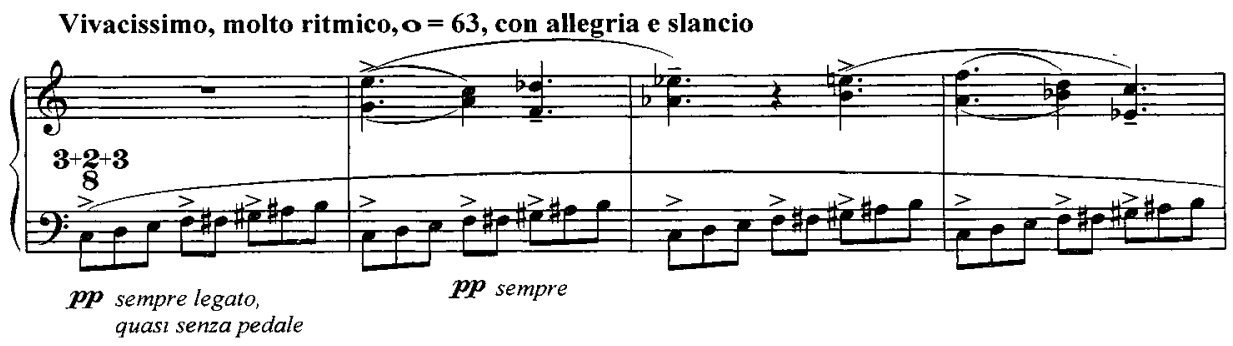

\section{Sintetizando}

A partir destas considerações e de minha experiência pessoal como pianista, concluo - ou reitero - que a modernidade não se revela através de aspectos específicos de notação, linguagem ou narrativa, mas na mensagem musical propriamente dita. Perceber, compreender e revelar o novo depende exclusivamente da escolha certa na hora da escuta, e o primeiro responsável no processo de comunicação entre compositor e os ouvintes é, sem dúvida, o intérprete.

Quando abordamos certas obras, baseando-nos em parâmetros préestabelecidos, sem discernimento, corremos o risco de perder de vista a dimensão e a intensidade da mensagem musical. Na verdade, esperar-se-ia que nossos ouvidos contemporâneos já estivessem libertados das amarras desses parâmetros restritivos, somente compreensíveis, como observamos, em ouvidos do início do século $X X$ : 
Finalmente, o que Saint-Säens (1911) chamou de anarquia foi na verdade o primeiro passo para o estabelecimento da liberdade de pensamento e expressão, que fundamentada consistentemente, possibilitou a modernidade.

\section{Referências}

BARRAQUÉ, Jean. Debussy. Paris: Editions du Seuil, 1994.

BHARUCHA, Jamshed J. Tonality and expectation. In AIELLO, Rita; SLOBODA, John (Eds.). Musical Perceptions. New York: Oxford University Press, 1994. p. 213-239.

BOTSTEIN, Leon. 1990. Time and Memory: Concert Life. Science and Music in Brahms's Vienna. In: FRISH. Walter (Ed.). Brahms and His World. New Jersey: Princeton University Press. p. 3-21.

BOULIANE, Denys. Six Études pour piano de Ligeti. Contrechamps, 12-13, p. 98-132, 1990.

BOURRIAUD, Nicolás. Ser Moderno no século XXI é olhar para o passado. Entrevista por Fabio Cypriano. Folha de São Paulo, 16 de outubro de 2006. Ilustrada.

BURGE, David. Twentieth-Century Piano Music. New York: Schirmer Books, 1990.

BURKHART, Charles. Anthology for Musical Analysis. New York: Harcourt Brace College Publishers, 1992.

CHUEKE, Zélia. Reading Music: a listening process breaking the barriers of notation. Per Musi, v. 11, p. 106-112, 2005.

Music Never Heard Before: the fear of the unknown. Revista MusicaHodie, v. 3. n. 1-2, p. 100-104, 2003.

COOK, Nicholas. Perception: a perspective from music theory. In: AlELLO, Rita; SLOBODA. John (Eds.). Musical Perceptions. New York: Oxford University Press, 1994. p. 64-95.

DEBUSSY, Claude. Jardins sous la pluie. In: Claude Debussy Piano Music. New York: Dover, 1973. Partitura.

. Mouvement. In: Claude Debussy Piano Music. New York: Dover, 1973. Partitura.

. Douze Études pour le piano. Paris: Durand, 1916. Partitura.

DOMMEL-DIÉNY. Amy. L'analyse harmonique en exemples: de J.S. Bach a Debussy. Neuchatel, Suisse: Delachaux et Niestlé, 1967. (Fascicule 16). 
DAVIDSON, Lyle; WELSH. Patricia. Tonal structure and children's early learning of music. In: SLOBODA, John (Ed.). Generative Processes in Music: The Psychology of Performance, Improvisation, and Composition, London: Oxford University Press, 2001. p. 260-285.

DE LA LAURENCIE, L. Notes sur l'art de Claude Debussy. Le Courrier Musical, $7^{e}$ année, n. 5. p. 141-149, 1904.

DOWLING, Jay W. Tonal structure and children's early learning of music. In: SLOBODA, John (Ed.). Generative Processes in Music: The Psychology of Performance, Improvisation, and Composition. London: Oxford University Press, 2001. p. $113-128$.

ERISMANN, Guy. Janáček ou la passion de la vérité. Paris: Seuil, 1990.

FRISH, Walter. Brahms, Developing Variation and the Schoenberg Critical Tradition. 19th Century Music, vol. V, n. 3. p. 215-231, Spring 1982.

GILLY, Cécile: SAMUEL, Claude (Ed.). Acanthes an XV: composer, enseigner, jouer la musique d'aujourd'hui. Fondettes: Van de Velde, 1991.

GRABOCZ, Marta (Org.). Méthodes d'analyse concernant la forme sonate autour du premier mouvement de l'op. 53 "Waldstein" de Beethoven. In: . Méthodes nouvelles, musiques nouvelles. Strasbourg: Presse Universitaire, 1999. (Tradução publicada na revista Cognição e Artes Musicais, Curitiba, v. 2, 2007).

GOUBAULT, Christian. Claude Debussy, la musique à vif. Paris: Minerve, 2002.

HAIMO, Ethan. Schoenberg and the Origins of Atonality. In: BRAND, Julian; HAILEY. Christopher (Eds.). Constructive Dissonance: Arnold Schoenberg and the Transformation of the $20^{\text {th }}$ Century. Berkeley. LA: Arnold Schoenberg Institute, 1997. p. 71-86.

JANÁČEK, Leoš. Concertino. A6385. Miami: Kalmus, [s.d.]. Partitura.

Sonata 7.X.1905. Critical Edition. Prague: Suprapohn, 1978. Partitura.

LANDORMY, Paul. 1911. M. Claude Debussy et l'Avenir de la Musique Française. Le Courrier Musical, 13e année, n. 3, p. 98-101.

LANG, Henry: BRODER. Nathan. Contemporary Music in Europe: A Comprehensive Survey. New York: The Norton Library. 1968.

LIGETI. György. Études pour piano. Premier livre. Mainz: Schott, 1986. Partitura.

MACDONALD, Malcom. Brahms. London: J/M/Dent \& Sons, 1990.

MADURELL, François. Musique d'aujourd'hui oreille d'hier. In: GRABOCZ, Marta (Ed.). Méthodes Nouvelles musiques nouvelles: musicologie et création. Press Universitaire, 1999.

SCHOENBERG, Arnold. Harmonia. Trad. Marden Maluf. São Paulo: Fundação Editora da UNESP, 2002.

. Klavierstucke op. 11. Los Angeles: Universal Edition, 1910. Partitura. 
SCHLOEZER, Boris; SCRIABINE, Marina. Problémes de la Musique Moderne. Paris: Minuit, 1959.

STUCKENSCHMIDT, Hans Heinz. Arnold Schoenberg. Paris: Fayard, 1993.

VIRET, Jacques. 2001. Entre Sujet et objet: I'herméneutique musicale comme méthodologie de l'écoute. In: (Ed.). Approche herméneutique de la musique. Strasbourg: Presse Universitaire, 2001. p. 283-296.

A autora agradece em particular ao aluno Fernando Nicknich, monitor da disciplina HA063 do curso de Produção Sonora da UFPR, pela colaboração na edição dos exemplos musicais deste artigo.

Zélia Chueke: zchuekepiano@ufpr.br

Artigo recebido e aprovado em 10 de maio de 2007 